\title{
Estado e Empreiteiras II: Permeabilidade e Políticas Urbanas em São Paulo (1978-98)*
}

\author{
Eduardo Cesar Marques \\ Renata Mirandola Bichir
}

\section{INTRODUÇÃO}

— - desenrolar de uma política pública. Estudamos a relação entre Estado e empresas privadas na produção e gestão da política de infra-estrutura urbana na cidade de São Paulo, entre 1978 e 1998, executada pela Secretaria Municipal de Vias Públicas -SVP. O artigo dialoga intensamente com pesquisa anterior sobre tema similar, referente à política de saneamento básico no Rio de Janeiro, entre 1975 e 1996, consubstanciada em Marques (1999a; 2000).

No estudo sobre política de saneamento, foram analisados os padrões de vitória de empreiteiras em licitações, que se revelaram extremamente concentrados. Na explicação desse fenômeno, destacamos a estruturação dos vínculos entre indivíduos, grupos e entidades em

\footnotetext{
* Versão preliminar deste texto foi apresentada no III Encontro da Associação Brasileira de Ciência Política - ABCP, realizado em Niterói, em julho de 2002. Agradecemos as críticas gentis e precisas de Gilberto Hochman, comentarista da mesa, assim como as de vários colegas do plenário. As observações foram, na medida do possível, incorporadas ao texto. Desnecessário dizer que as imprecisões restantes continuam sendo de nossa inteira responsabilidade.
}

DADOS - Revista de Ciências Sociais, Rio de Janeiro, Vol. 46, no1, 2003, pp. 39 a 74. 
redes de relações no interior da comunidade dos engenheiros, construindo analiticamente a categoria "permeabilidade" para dar conta dos limites e interpenetrações entre público e privado no desenrolar da política de saneamento. A especificação da permeabilidade foi possível graças ao estudo detalhado dos vínculos entre indivíduos e empresas, realizado mediante a análise de redes sociais. O estudo da rede mostrou que a concentração de vitórias em algumas poucas empresas privadas podia ser explicada pelas posições ocupadas por elas na rede da comunidade em cada governo.

Na presente pesquisa, examinando os padrões de vitória e a estrutura da rede de relações de outra comunidade de política urbana - a de infra-estrutura urbana - em uma outra grande cidade brasileira, São Paulo, comprovamos a importância da dimensão relacional da comunidade. A política inclui projetos e obras de drenagem, pavimentação, sistema viário, abertura de vias e grandes estruturas (pontes, viadutos e túneis). A comparação dos dois casos, entretanto, mais do que simplesmente confirmar os processos observados anteriormente, demonstra a existência de inúmeras particularidades nos diferentes processos decisórios. Estas apontam para uma especificação do padrão geral de relações entre Estado e sociedade, segundo a estrutura do jogo político e a dinâmica do poder em cada cidade. Em termos comparativos, ambos encerram situações muito diferentes. Na política de saneamento no Rio de Janeiro, estudamos uma empresa pública com receita própria e trajetórias de carreira bem definidas, o que originou uma burocracia relativamente insulada e bastante fechada, estruturada em uma rede polarizada em diversos grupos. Na política de infra-estrutura urbana em São Paulo, analisamos um órgão da administração direta que depende de repasses da Prefeitura para sua sobrevivência financeira, apresenta intensas migrações para outros órgãos do setor público e é estruturado sobre uma rede menos densa e menos dinâmica, hegemonizada na maior parte do tempo por um único grupo.

Do ponto de vista do poder, o caso do Rio de Janeiro envolve uma política de expressão bem menos central do que o de São Paulo, onde a Secretaria é ocupada, durante a maior parte do tempo, por importantes quadros técnico-políticos do grupo político que controla a administração municipal, e que encerra algumas das iniciativas de política mais importantes para esse grupo. 
O artigo é composto de quatro seções, além desta introdução. Na primeira, discutimos os pressupostos conceituais e situamos o leitor em relação à análise de redes e às peculiaridades da sua aplicação ao caso brasileiro. Na segunda seção, expomos as principais características da política de investimentos da SVP, assim como as dimensões gerais do padrão de vitória de empreiteiras. Em seguida, apresentamos a rede da comunidade dos engenheiros e mostramos como a ocupação pelas empresas de determinadas posições na rede, em cada governo, explica uma parcela considerável do fenômeno. As diferenças e as semelhanças entre esse padrão e o encontrado no Rio de Janeiro permitem discutir as relações entre público e privado no Brasil de forma mais ampla, o que fazemos na quarta e conclusiva seção.

\section{REDES E PERMEABILIDADE NO BRASIL}

Para uma parte significativa da literatura de ciências sociais e para praticamente todo o senso comum, o Estado brasileiro teria como uma de suas principais características a interpenetração entre suas agências e atores privados. Esse elemento constitutivo teria como conseqüências a formação de "anéis burocráticos", que englobariam grupos do Estado e do setor privado (Cardoso, 1970), a privatização e a segmentação do Estado (Grau e Belluzzo, 1995), ou mesmo a privatização de políticas específicas, como as políticas sociais (Draibe, 1989). A origem de tal fenômeno estaria, em sentido macrossocial, nas próprias relações entre Estado e classes dominantes no Brasil (Cardoso, 1970), mediadas por "círculos de interessados" que substituiriam as "organizações intermediárias" - partidos, sindicatos e organizações voluntárias - pouco importantes na canalização de interesses do país, ou então no desenho equivocado das instituições brasileiras, que incentivariam o personalismo, o clientelismo e a corrupção (Geddes e Ribeiro Neto, 2000).

Em uma dimensão mais microssocial, a origem dos problemas estaria na presença do "individual, [...] inserido no Estado, [...] na determinação do interesse público" (Grau e Belluzzo, 1995:7), na continuada presença de hierarquias, mesmo após a disseminação dos mecanismos de mercado (Lanna, 1997); na importância das relações pessoais na estruturação do poder político, mesmo no interior da sociedade contemporânea brasileira (Bezerra, 1995; 2000); na dissociação entre indivíduo e pessoa nas relações sociais (DaMatta, 1978) ou na manutenção de práticas de troca restrita concomitantemente com o desen- 
volvimento de padrões de troca generalizada, o que levaria à persistência da gramática política do clientelismo, mesmo que interpenetrada pelas gramáticas do corporativismo, do insulamento burocrático e do universalismo de procedimentos construídas posteriormente (Nunes, 1997).

Apesar da constatação do fenômeno e do destaque de suas conseqüências em sentido macrossocial, ou da descrição dos microfundamentos desses macroprocessos, a literatura brasileira de ciências sociais não tentou descrever detalhadamente a interpenetração entre Estado e agentes privados, e tampouco compreender os processos através dos quais esta foi produzida e é reproduzida no cotidiano da vida política brasileira. Talvez por essa razão, uma parcela significativa dos diagnósticos recentes sobre a crise do Estado brasileiro do debate acadêmico, assim como os receituários para a sua solução, presentes no debate político, sejam muito abstratos, ou excessivamente formalistas. No primeiro caso, as análises podem ser úteis na construção de uma crítica aos pressupostos do debate, mas dificilmente levam à elaboração de alternativas ${ }^{1}$, enquanto no segundo se creditam possibilidades quase ilimitadas à reforma institucional e às mudanças de desenho, sem considerar devidamente a dinâmica política ou o funcionamento concreto de agências e instituições (ver, p. ex., Bresser Pereira, 1998) $)^{2}$.

Recentemente, alguns estudos começaram a constituir um campo analítico que permitiu compreender os padrões de relação entre público e privado no Brasil com maior complexidade e de forma mais precisa. Na verdade, essas análises não tentam descrever o "Estado como ele deve ser, [mas]... como ele é" (Grau e Belluzzo, 1995:13), o que pressupõe compreender o Estado brasileiro de forma a escapar da dicotomia atraso/moderno implícita em boa parte da literatura. Um dos trabalhos recentes mais importantes nessa linha é o de Nunes (1997), que mostra que as linguagens políticas - ou as gramáticas - da relação entre Estado e sociedade foram sendo retrabalhadas historicamente a partir das gramáticas anteriores. Tentando descrever e compreender as relações entre público e privado em detalhes e analisar o cotidiano das práticas advindas dessas relações, podemos citar os trabalhos de Bezerra (1995), que estudou a importância dos padrões de relação pessoal em episódios de corrupção em obras federais, e de Marques (1999a; 2000), que levantou as redes de relações no 
interior da comunidade e explicou, a partir delas, vários aspectos da política de saneamento no Rio de Janeiro.

O presente artigo dá continuidade a essa tarefa, realizando uma análise detalhada das relações entre Estado e atores privados em uma política urbana, com resultados comparáveis aos de Marques (idem; idem). Assim, ao mesmo tempo que são apresentados os resultados da experiência paulistana, estes são comparados com o caso carioca, de forma a destacar as particularidades de cada um e, assim, ajudar na compreensão do padrão geral (Tilly, 1992), iluminando as relações entre o público e o privado nas políticas públicas brasileiras.

Não cabe aqui resenhar a literatura de redes sociais na ciência política, tarefa já efetuada em Marques (2000), mas apenas delimitar o uso que faremos dela e destacar suas conseqüências para nosso estudo. A análise de redes permite o estudo das relações entre Estado e setor privado no desenrolar de uma política sem delimitar previamente os dois campos - o público e o privado -, já que a unidade básica de análise é a relação, e não os atributos dos indivíduos e entidades como, por exemplo, pertencer a essa ou àquela agência ou ao setor privado. A idéia mais geral é que indivíduos, grupos e organizações, no exercício de suas atividades cotidianas, assim como de suas estratégias, constituem redes de relações entre si. Estas, concomitantemente, são parte importante da dinâmica do social e cristalizam-se em redes, que operam como estruturas de médio alcance sobre os acontecimentos posteriores, inclusive sobre a sua própria transformação, pelo lançamento e quebra de novos vínculos. Uma vez constituídas, essas redes influenciam o desdobramento do processo político.

Naquilo que nos interessa mais diretamente neste trabalho, as redes influem no desenvolvimento das políticas públicas e estruturam as relações (e a interpenetração) entre os campos do público e do privado, já que os técnicos de ambos os setores foram formados nas mesmas universidades, compartilham da mesma comunidade técnica e profissional, além de se relacionarem no interior da sociedade mais ampla. A nossa hipótese é que as redes das comunidades de política estruturam as relações entre público e privado na explicação da permeabilidade do Estado (idem). Mais especificamente, como veremos ao longo deste artigo, a permeabilidade explica o padrão de vitória de empreiteiras em licitações, já que, para além da presença de corrupção tão destacada na literatura, um dos principais insumos nesse tipo 
de disputa - as informações - circula pela rede e o acesso a eles é regulado pela ocupação de posições diferenciadas na mesma.

\section{INSTITUIÇÕES POLIITICAS, REDES SOCIAIS E CONTRATAÇÕES DO SETOR PÚBLICO}

Em um sentido bem geral, os efeitos sobre a dinâmica social das instituições políticas e das redes assemelham-se, já que ambas estruturam os ambientes onde os processos políticos se dão. Com relação ao efeito das primeiras, a literatura neo-institucionalista já estabeleceu um ponto de difícil questionamento (Skocpol, 1992; Steinmo et alii, 1992; dentre muitos outros). Para os neo-institucionalistas, especialmente os históricos, as instituições agiriam como molduras da política e das políticas, não apenas influenciando resultados, mas alterando as próprias preferências dos atores, ao definir possibilidades e probabilidades para diferentes estratégias, alianças e linhas de ação (Steinmo et alii, 1992). De forma similar, as redes alteram os resultados dos processos políticos, assim como alteram estratégias e até mesmo preferências de atores e grupos. Esse efeito não é mutuamente exclusivo, mas, ao contrário, ocorre de forma concomitante e paralela. Assim, embora analisemos aqui a influência das redes na estruturação dos campos do público e do privado no Brasil, não podemos deixar de considerar que isso ocorre no interior de um ambiente institucional específico e que as características desse ambiente, assim como suas alterações, também apresentam grande importância.

A relação entre redes e instituições também fica evidente na importância diferenciada entre as redes do Rio de Janeiro estudadas por Marques (2000) e as de São Paulo analisadas aqui. Como veremos, as duas redes apresentam influências bastante diversas sobre a permeabilidade do Estado no desenrolar da política. Na do Rio de Janeiro, havia uma influência muito maior do chamado poder posicional sobre as vitórias das empresas, representado pela importância de vínculos construídos paulatinamente ao longo das carreiras dos técnicos, em grande parte de maneira não intencional. Nesse caso, a relação das empresas com o poder institucional - advindo da ocupação de cargos - é em grande parte mediada pelo poder posicional. No que diz respeito a São Paulo, ao contrário, parece ser muito mais definidora da permeabilidade a proximidade, na rede, do poder institucional ${ }^{3}$. 
Como veremos, um elemento importante na explicação do padrão paulistano tem a ver com a centralidade da direita nas administrações municipais no período estudado, assim como com a construção, por esses governos, de preferências de políticas bastante claras, em que certamente um tipo de permeabilidade e relação com o setor privado está presente. Entretanto, acreditamos que um outro elemento também seja muito importante para explicar por que os padrões de permeabilidade dos dois casos são tão diferentes, e nesse ponto voltamos às instituições. Uma outra grande diferença entre ambos está no desenho das duas agências analisadas, sendo a do Rio de Janeiro mais insulada, estável em termos de padrão de carreira e independente em termos financeiros. Acreditamos que a maior institucionalização da agência carioca, comparada com a paulistana, explica parte considerável da força de sua rede (e das posições no seu interior) nas negociações de poder que se estabelecem, de um lado com o poder institucional da classe política e seus gestores de livre indicação, e de outro com o poder econômico das empresas que são contratadas nesse setor. Voltaremos a este ponto nas últimas seções.

Dentre as instituições presentes no ambiente político, a mais importante para a regulação das relações entre público e privado no Brasil é o marco legal que regula as licitações. No Brasil, as contratações públicas são precedidas necessariamente de processos administrativos padronizados denominados licitações. Não faremos uma resenha sobre o assunto, e tampouco um histórico da legislação, tarefa já realizada em Marques (idem), mas comentaremos rapidamente os aspectos mais relevantes da dinâmica dessa legislação em período recente, de forma a melhor situar o leitor com relação ao ambiente que cerca os contratos, assim como suas alterações ao longo do período.

Apesar de as licitações regularem as compras e as contratações de obras e serviços do setor público, a primeira legislação específica sobre licitações foi promulgada apenas em 1986 (Decreto-Lei nº $2.300 / 86)$. Até esta data, os processos de contratação eram regulados pelo Código de Contabilidade da União de 1922, que estabelecia os princípios de probidade, publicidade e igualdade para as ações dos agentes públicos, e pelo Decreto-Lei no 200/67, que instituía uma ampla reforma administrativa, além de legislações pontuais e sobre aspectos específicos firmados ao longo dos anos (Meirelles, 1995). Assim, o ano de 1986 representa um marco no ordenamento jurídico brasileiro relativo à matéria, fixando os tipos de licitação, descreven- 
do detalhadamente a documentação técnica exigida para a contratação, estabelecendo com minúcias as condições de dispensa, além de discorrer sobre inúmeros detalhes ao longo dos seus noventa artigos.

Depois dessa legislação, a alteração subseqüente de vulto no arcabouço jurídico ocorreu em 1993, com a promulgação da Lei Federal no 8.666/93. Elaborada sob o impacto do escândalo do Orçamento Geral da União e do imbróglio de PC Farias/Collor de Mello, esta lei apresenta características bem mais restritivas que a legislação de 1986, chegando a tipificar crimes e a estabelecer penas para os infratores dos procedimentos administrativos de contratação $0^{4}$. Essa rigidez foi posteriormente reduzida na Lei Federal no 8.883/94, mas o detalhamento da matéria permaneceu elevado.

Como veremos, os momentos de mudança da legislação sobre licitações coincidem com transformações nos padrões de concentração de vitórias, indicando uma forte influência do arcabouço institucional sobre a dinâmica da política. Esse fenômeno já estava presente no caso do Rio de Janeiro analisado por Marques (1999a; 2000), mas as informações sobre São Paulo confirmam a sua ocorrência.

Um último esclarecimento diz respeito à utilização, neste trabalho, da corrupção como conceito. Em termos conceituais, queremos diferenciar três processos, usualmente considerados genericamente como corrupção, embora nos casos empíricos eles possam estar associados ou ocorrerem de maneira independente. A realização de licitações e contratos, resguardando o interesse público, pressupõe que sejam preservados três elementos: prazo, qualidade e preço. Portanto, caso um destes seja violado, em uma dada obra ou serviço, se estará lesando o interesse público. A realização do processo de licitação pressupõe que, através da competição entre as empresas por contratos com o Estado, se estabeleçam as melhores condições para este último. Entretanto, caso um funcionário oriente o processo de contratação, escolhendo uma empresa, não necessariamente o interesse público estará sendo lesado, desde que o serviço possa ser realizado no prazo, com boa qualidade e pelo preço justo. Neste caso, o funcionário estará lesando o mercado de obras públicas e, mais especificamente, as outras empresas que não puderam concorrer em igualdade de condições. Embora para o senso comum esses dois procedimentos sejam equivalentes à corrupção, entendemos que é necessário delimitar mais o conceito de forma a circunscrever uma prática única. Assim, seguin- 
do Pasquino (1993), consideramos como corrupto o ato de um funcionário que viola o conjunto de seus deveres, de forma ativa ou passiva, em troca de recompensa ou promessa de recompensa material ou imaterial.

Como tem sido fartamente noticiado pela imprensa e pelo Ministério Público Federal de São Paulo, ocorreram lesões ao mercado e ao Estado, assim como corrupção no desenrolar da política de infra-estrutura urbana em São Paulo durante o período estudado ${ }^{5}$. Como fenômeno, a corrupção se encontra imbricada com diversas facetas da política e, em termos relacionais, é um dos tipos de vínculo presente no setor. Apesar disso, do nosso ponto de vista, a corrupção não encerra a política. O exame da política pública, portanto, não se reduz à análise da corrupção e podemos estudar (e explicar) inúmeros processos, inclusive os padrões de vitória de empreiteiras, sem nos referirmos a ela diretamente. Nesse sentido, tratamos a corrupção como um dos tipos de vínculo entre indivíduos, grupos e empresas na rede, incluindo-a nas entrevistas realizadas. As informações sobre corrupção advindas das entrevistas permitiram recompor uma das camadas da rede, a de corrupção, que se articulou com os demais tipos de vínculo (políticos, pessoais e de trabalho) na reconstrução da rede.

\section{Empresas de Construção, Mercado Nacional e Mercado Local}

As empresas privadas de construção representam um dos mais destacados setores das empresas nacionais na economia brasileira, constituindo, para alguns autores, um dos principais sustentáculos da chamada tríplice aliança entre o capital nacional, o multinacional e o Estado, tripé que instaura e desenvolve o capitalismo no Brasil (Lessa e Dain, 1982). Sua importância foi sendo desenvolvida paulatinamente, desde o início do processo de contratação, pelo Estado, de empresas privadas para a construção de obras e serviços de engenharia na década de 40 (Camargos, 1993).

A consolidação histórica desse campo levou à construção de grandes empresas capitalizadas e de padrão tecnológico altamente especializado até o início dos anos 70, que tinham hegemonia sobre esse mercado em nível nacional, sendo responsáveis por grande parte das obras dos setores de transportes e energia durante o regime militar. No decorrer das décadas de 70 e 80, esse grupo se internacionalizou, e 
outros conjuntos de empresas de menor porte passaram a assumir o controle de mercados locais e menos intensivos em tecnologia, como as obras de infra-estrutura urbana.

No que diz respeito à dinâmica recente do mercado brasileiro de obras públicas, sua situação pode ser expressa pela posição das mais importantes empreiteiras na economia nacional. Como já descrito em Marques (1999a; 2000), o número de empreiteiras entre as maiores empresas privadas brasileiras manteve-se em um patamar elevado entre meados dos anos 70 e a primeira metade da década de 80 , tendendo a cair continuamente a partir daí: dentre as 500 maiores empresas brasileiras, segundo a revista Exame, as de construção eram 27 em 1975, 37 em 1984, 28 em 1989, 16 em 1996 e apenas 8 em 1999. A posição média das empresas na lista também acompanha esse comportamento, embora, neste caso, a piora aconteça antes. A posição média das oito empresas mais bem colocadas foi de: $63^{\underline{a}}$ em 1975, 69ª em 1979,

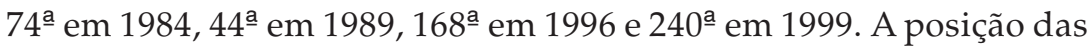
líderes melhorou entre 1975 e o final da década de 80, mas acompanhou a crise a partir de então: a posição média das três empresas mais bem colocadas foi de $37^{\mathrm{a}} \mathrm{em} 1975,2^{\mathrm{a}} \mathrm{em} 1979,22^{\mathrm{a}}$ em $1984,16^{\underline{a}} \mathrm{em}$ 1989, 78 a em 1996 e, finalmente, 103aㅡ em 1999.

As empresas vencedoras das licitações da SVP, na sua grande maioria, não fazem parte desse seleto clube de empreiteiras de grande porte envolvidas com as obras federais de construção pesada. A maior parte das empresas vencedoras é de porte médio e pequeno e atua no Estado de São Paulo principalmente em obras de infra-estrutura viária e de drenagem contratadas por prefeituras e pelo governo do estado. Sua organização típica é de natureza familiar, mesmo nas líderes locais de porte médio. Entretanto, assim como no caso das grandes empreiteiras de construção pesada, são comuns os vínculos das empresas, mesmo aquelas de porte médio, com os círculos políticos locais. O caso mais notório no cenário paulista é o da família Penido, dona e controladora da empresa Serveng Civilsan, uma das mais freqüentes vencedoras de licitações, importante referência da elite política e econômica do Vale do Paraíba paulista, tendo inclusive um de seus membros ocupado cargo de deputado federal.

Em Marques (2000), desenvolveu-se a hipótese de que o mercado de obras públicas se estrutura de forma hierárquica em escalas distintas, cada uma integrando redes de relações pessoais e institucionais dife- 
rentes, parcelas distintas da classe política, circuitos de corrupção específicos e tipos de obras e empresas diferentes. Por essa razão, podemos falar de empresas típicas do setor que, como veremos, são as mais integradas nas redes de relações da comunidade e, no caso das obras urbanas de infra-estrutura, são originárias de locais próximos à cidade onde se executam as obras, apresentam porte médio e estrutura familiar de gestão. Entretanto, invasões de firmas de escalas superiores são possíveis, motivadas em especial por crises nos mercados de maior vulto, caracterizados por obras de grande porte, mais intensivas em equipamentos e tecnologia, mais concentradas espacialmente e, portanto, mais lucrativas para as empresas de maior porte.

Como veremos, essas invasões ocorreram a partir do final dos anos 80 tanto nas obras de saneamento no Rio de Janeiro, analisadas por Marques (2000), quanto nas intervenções de infra-estrutura urbana, que serão analisadas nas próximas seções. Na maior parte do período, entretanto, os vencedores de licitações de infra-estrutura no âmbito local correspondem ao que denominamos de empresas do setor-locais, de porte pequeno e médio, gestão pouco profissionalizada e padrões intensos de relação com as redes da comunidade.

\section{SVP, A POLÍTICA MUNICIPAL EM SÃO PAULO E SUAS POLÍTICAS}

A pesquisa baseou-se em amplo levantamento de dados primários no Diário Oficial do Município de São Paulo, sendo analisadas todas as contratações efetuadas pela Secretaria Municipal de Vias Públicas com empresas privadas, entre 1978 e 1998. Além das contratações diretas da Secretaria, são cobertas pela pesquisa as intervenções gerenciadas pela Empresa Municipal de Urbanização - EMURB, extremamente importantes por representarem as maiores obras, executadas pelas maiores empreiteiras, como será esclarecido ao longo do artigo. As contratações totalizam 3.350 contratos, além de aditamentos, retificações e aprovações de preços, vencidos por cerca de 350 empreiteiras, e os contratos somam $\mathrm{R} \$ 8,5$ bilhões (valores para dezembro de 1999) 6 .

Por não possuir receitas próprias e depender de repasses do orçamento municipal, o volume de investimentos da Secretaria é muito variável ao longo do período analisado, indicando as diferentes prioridades políticas dos administradores municipais. Apesar disso, o valor médio (13\%) de participação dos gastos da Secretaria no orçamento municipal é bastante elevado, se considerarmos que suas atividades 
se referem apenas a investimentos e não envolvem gastos significativos com custeio, como nos casos das Secretarias de Educação e Saúde. Em algumas administrações, como a de Paulo Maluf, a participação média da SVP chegou a $18 \%$, com investimentos de até $27 \%$ do orçamento em 1993, cerca de R \$2,5 bilhões. Em outros governos, como os de Luiza Erundina e Mário Covas, as participações médias dos gastos não chegaram a $9 \%$.

Uma análise detalhada dos investimentos da SVP e de seus condicionantes já foi empreendida por nós em Marques e Bichir (2001a; 2001b; 2001c). Entretanto, de forma a melhor situar o leitor com relação aos mais importantes condicionantes dos investimentos, serão apresentados os principais padrões encontrados, especialmente delimitados pela clivagem político-ideológica entre direita e esquerda, que se mostrou estatisticamente significativa na explicação dos investimentos da Secretaria ${ }^{7}$. Ao contrário do que se poderia esperar com base no senso comum e em parcela da literatura especializada, não se encontrou relação estatística significativa entre ciclos eleitorais e ciclos de investimentos, e tampouco associação do volume de investimentos com a maior disponibilidade de recursos no orçamento municipal (Marques e Bichir, 2001a).

Governos de direita apresentam um padrão de investimentos bastante característico: concentrado em poucos contratos, de alto valor unitário, aditados intensamente (muitas vezes acima do limite legal) ${ }^{8}$, vencidos geralmente por empreiteiras de elevado capital médio, além de dispensas de licitação de elevados valores. Em termos espaciais, a direita tende a investir sistematicamente mais em áreas de alto padrão, habitadas pela população mais bem inserida socialmente, reforçando, desse modo, a segregação socioespacial ${ }^{9}$.

Administrações de esquerda, por sua vez, apresentam investimentos mais dispersos em obras pequenas e médias, realizadas por meio de contratos de menor valor unitário, aditados menos intensamente, vencidos por empreiteiras de menor capital médio. Em termos espaciais, os administradores de esquerda tendem a privilegiar as áreas habitadas pelos grupos sociais menos favorecidos.

Além da clivagem político-ideológica, outro importante fator condicionante do volume anual de investimentos se refere à presença das empresas privadas na rede de relações da comunidade. Foram encon- 
tradas duas variáveis estatisticamente relacionadas com os investimentos da SVP: a magnitude da presença de empreiteiras na rede de cada período e a proximidade média dessas empresas ao núcleo do poder decisório ${ }^{10}$. Esta descoberta sugere que a política de infra-estrutura viária é fortemente estimulada pelas empresas do setor. Estas se constituiriam em um tipo especial de "consumidor" da política, muito diferente do cidadão que usa a infra-estrutura na cidade, embora as empresas se situem do lado da oferta, se considerarmos a linha de produção das políticas. Os resultados das próximas seções especificam este argumento.

\section{Concentração Geral dos Contratos, Dinâmica Política e Regras Institucionais}

A primeira dinâmica relativa às empresas nas obras da SVP diz respeito à concentração das vitórias. Os investimentos da SVP apresentam um padrão extremamente concentrado, semelhante ao observado no Rio de Janeiro no caso da Companhia Estadual de Águas e Esgotos-CEDAE. A maior parte deles é contratada com algumas raras empresas que vencem alguns poucos contratos, de elevado valor unitário. A maior vencedora alcançou um valor total de $\mathrm{R} \$ 880$ milhões, aproximadamente, em um total de apenas dois contratos. Esta empresa, apesar de representar somente $0,3 \%$ do universo de empresas, beneficiou-se de $10,3 \%$ do total investido pela Secretaria. Os dez maiores vencedores, $2,8 \%$ do universo de empresas, receberam $51,7 \%$ dos investimentos. Essa concentração de vitórias nas mãos de poucas firmas é maior do que a observada no caso da CEDAE, em que a principal empresa recebeu 8,5\% do total investido, e as dez maiores $46,6 \%$.

Contudo, a concentração de vitórias apresenta diferentes dinâmicas ao longo do tempo, como podemos verificar no Gráfico 1, que mostra a participação do valor total anual recebido por cada grupo de empresas: os 5\%,10\% e 35\% maiores vencedores em cada ano, assim como os $50 \%$ menores vencedores. O balanço geral do período mostra um aumento da proporção de investimentos recebidos pelos $5 \%$ maiores vencedores, ao lado da redução dos recursos obtidos pelos menores (os 50\% menores receberam frações ínfimas do total investido, não chegando a 10\%). Além disso, podemos notar a existência de dois períodos distintos na concentração dos $5 \%$ maiores vencedores. Naquele que vai de 1978 a 1986, observa-se uma pequena participação dessas empresas, ao contrário do que se estende de 1987 a 1998. Em am- 
Gráfico 1

Proporção de Valor Investido Recebido por Empresa

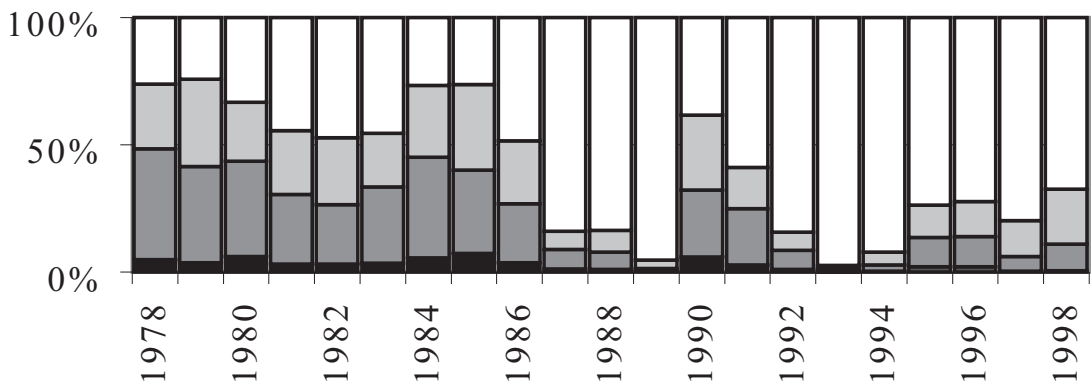

$50 \%$ menores

$\square$ próximos $10 \%$ maiores próximos $35 \%$ maiores

$5 \%$ maiores

Fonte: Diário Oficial do Município de São Paulo.

bos os períodos ocorrem reduções da concentração em administrações de esquerda - 1984 e 1985 e entre 1990 e 1991. A maior concentração do segundo período pode ser creditada à realização dos contratos da EMURB que, como já foi dito, representaram a entrada das grandes empreiteiras de construção pesada no mercado local.

A diferença entre as proporções das maiores e menores vencedoras fica ainda mais evidente no Gráfico 2. Neste, a área mais escura indica os valores obtidos pelos $15 \%$ maiores vencedores em cada ano, e a área mais clara, entre a primeira e a curva do total investido, representa o volume de recursos anuais vencidos pelos $85 \%$ menores vencedores. Seguindo um fenômeno observado no caso da CEDAE, também no caso dos investimentos da SVP, as pequenas empresas só conseguem receber mais, relativamente, nos momentos de elevação dos investimentos totais da Secretaria, quando os ganhos das maiores empresas já estão garantidos. Estas acolhem, relativamente, os maiores investimentos e sempre têm uma proporção elevada garantida de ganhos, confirmando a hipótese da estruturação hierárquica do mercado de obras públicas já adiantada.

O comportamento anual da concentração ainda apresenta uma última dinâmica que merece ser destacada. Paralelamente à elevação da concentração em valor ao longo do tempo, já destacada e apresentada no Gráfico 1, tem ocorrido uma redução da concentração em número 
Gráfico 2

Investimentos e Valores Ganhos pelos Maiores Vencedores

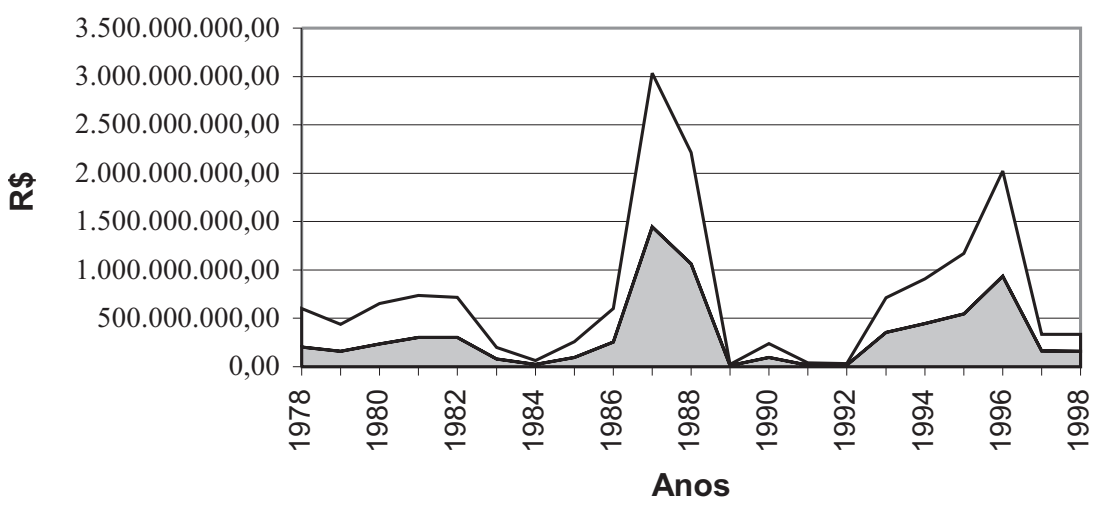

vencido pelas $15 \%$ maiores

$\square$ total investido

Fonte: Diário Oficial do Município de São Paulo.

de documentos vencidos por empresas distintas. As informações disponíveis indicam que esse processo é produto, ao menos em parte, das mudanças institucionais ocorridas no arcabouço jurídico que regula as licitações.

O Gráfico 3, além de exibir as curvas de concentração referentes aos dois universos estudados (São Paulo e Rio de Janeiro) e às duas políticas, de infra-estrutura e de saneamento básico, mostra o comportamento anual comparativo do índice de concentração de documentos, desenvolvido em Marques (2000), que expressa a relação entre as licitações realizadas em um determinado ano e o número de empresas vencedoras naquele ano, apontando para uma maior ou menor dispersão dos contratos assinados, já descontado o efeito das grandes variações anuais no número de vencedores e contratos. Pode-se perceber uma dinâmica muito similar nas duas curvas a partir de 1986, que aponta para uma redução do número de documentos vencidos (em média) por empresa por ano, indicando, por conseguinte, uma dispersão das vitórias nos dois casos. É importante observar que os momentos de maiores quedas nas curvas coincidem com a promulgação de legislação federal sobre licitações, indicando que o fenômeno 
Gráfico 3

Índice de Concentração de Vitórias em Licitações

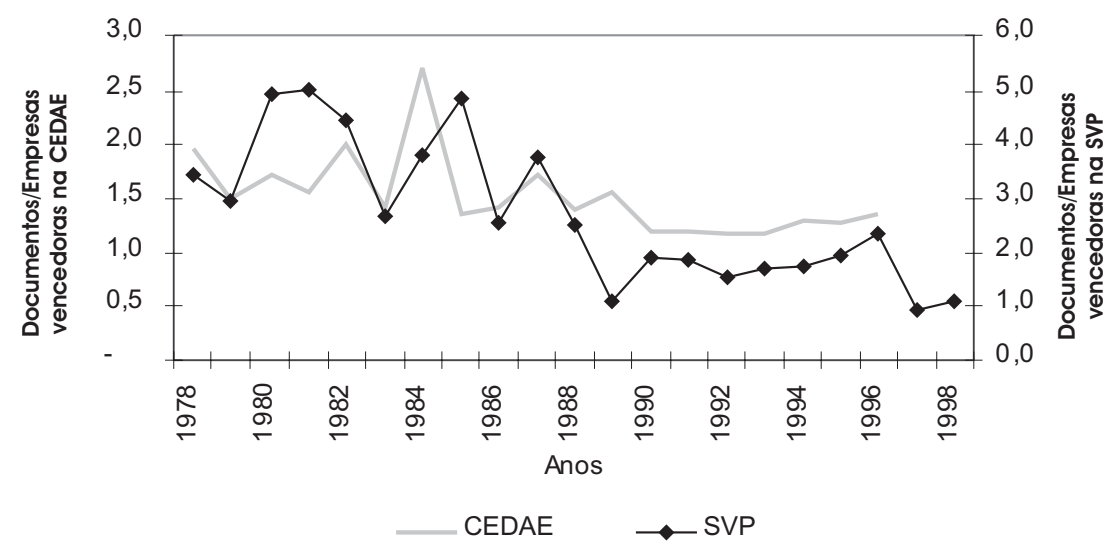

Fontes: Diário Oficial do Município de São Paulo; Marques (2000).

interveniente é de natureza institucional. Apesar do aparente paradoxo entre essa tendência à dispersão do número de documentos por empresas em um dado ano e a tendência à concentração dos valores obtidos pelas maiores vencedoras, citada anteriormente, esses dois fenômenos coexistem coerentemente, pois o fato de mais empresas competirem por recursos e vencerem licitações não implica que todas recebam a mesma proporção de investimento.

\section{Maiores vencedores}

Mas quem são os mais importantes vencedores das licitações da SVP? A Tabela 1 apresenta os valores totais e médios e o número de contratos obtidos pelas quarenta maiores empresas, responsáveis por $84 \%$ do valor licitado pela Secretaria no período ${ }^{11}$.

É interessante notar que um conjunto muito seleto dentre os maiores vencedores celebrou contratos por intermédio da EMURB. São eles ${ }^{12}$ : Andrade Gutierrez (MG), CR Almeida (PR/RJ), O.A.S. (BA), CBPO (SP), Camargo Corrêa (SP), Constran (SP), Cowan (MG) e Mendes Júnior $(\mathrm{MG})^{13}$. Algumas destas empresas, como a Andrade Gutierrez, a Camargo Corrêa, a CR Almeida e a Cowan, só foram contratadas pela EMURB (não obtiveram nenhum outro contrato com a Secretaria) para 
Estado e Empreiteiras II: Permeabilidade e Políticas Urbanas em São Paulo (1978-98)

Tabela 1

Maiores Vencedores de Contratos da SVP

\begin{tabular}{|c|c|c|c|}
\hline Vencedor & $\begin{array}{c}\text { Valor Total } \\
\text { (em R\$ de } \\
12 / 1999 \text { ) }\end{array}$ & $\begin{array}{c}\text { № de } \\
\text { Contratos }\end{array}$ & $\begin{array}{c}\text { Valor Médio } \\
\text { (em R\$ de } \\
12 / 1999)\end{array}$ \\
\hline Andrade Gutierrez & $883.794 .065,76$ & 2 & $441.897 .032,88$ \\
\hline CR Almeida & $557.408 .399,35$ & 1 & $557.408 .399,35$ \\
\hline Construtora O.A.S. Ltda & $516.573 .300,81$ & 2 & $258.286 .650,41$ \\
\hline $\mathrm{CBPO}$ & $498.158 .566,85$ & 12 & $41.513 .213,90$ \\
\hline Camargo Corrêa & $494.920 .901,91$ & 7 & $70.702 .985,99$ \\
\hline Constran & $441.667 .400,01$ & 10 & $44.166 .740,00$ \\
\hline Cowan & $351.699 .334,98$ & 1 & $351.699 .334,98$ \\
\hline Serveng Civilsan & $313.320 .073,59$ & 122 & $2.568 .197,32$ \\
\hline Mendes Júnior S/A & $236.450 .396,84$ & 18 & $13.136 .133,16$ \\
\hline Firpavi & 207.093.461,43 & 57 & $3.633 .218,62$ \\
\hline Queiroz Galvão & $179.407 .566,52$ & 14 & $12.814 .826,18$ \\
\hline Vega Sopave & $161.374 .499,28$ & 71 & $2.272 .880,27$ \\
\hline Convap & $147.730 .327,61$ & 16 & $9.233 .145,48$ \\
\hline Guaianazes & $144.794 .745,55$ & 117 & $1.237 .561,93$ \\
\hline Azevedo \& Travassos & $129.752 .799,81$ & 86 & $1.508 .753,49$ \\
\hline Heleno \& Fonseca & $128.465 .196,72$ & 73 & $1.759 .797,22$ \\
\hline Badra & $122.675 .105,61$ & 39 & $3.145 .515,53$ \\
\hline Camargo Campos & $117.119 .126,63$ & 115 & $1.018 .427,19$ \\
\hline Etesco & $117.100 .874,15$ & 17 & $6.888 .286,71$ \\
\hline Cogec & $112.281 .378,90$ & 94 & $1.194 .482,75$ \\
\hline São Luiz & $96.375 .065,18$ & 86 & $1.120 .640,29$ \\
\hline Emparsanco & $95.009 .396,89$ & 88 & $1.079 .652,24$ \\
\hline Enpavi & $94.690 .319,61$ & 104 & $910.483,84$ \\
\hline Construbase & $88.338 .571,24$ & 9 & $9.815 .396,80$ \\
\hline Vicente Matheus & $81.110 .354,61$ & 93 & $872.154,35$ \\
\hline Jofege & $78.694 .339,84$ & 83 & $948.124,58$ \\
\hline Logos Engenharia S/A & $75.815 .324,35$ & 9 & $8.423 .924,93$ \\
\hline Geofisa & $70.178 .421,25$ & 102 & $688.023,74$ \\
\hline Imobel & $63.869 .182,00$ & 7 & $9.124 .168,86$ \\
\hline Dos Arroios & $60.099 .493,29$ & 62 & $969.346,67$ \\
\hline Radial & $57.924 .090,91$ & 88 & $658.228,31$ \\
\hline Construcap CCPS & $56.877 .747,97$ & 59 & $964.029,63$ \\
\hline N.F. Motta & $55.994 .733,25$ & 65 & $861.457,43$ \\
\hline Cosag & $55.286 .736,99$ & 86 & $642.869,03$ \\
\hline Araguaia & $55.242 .667,62$ & 99 & $558.006,74$ \\
\hline Passarelli & $53.409 .151,82$ & 50 & $1.068 .183,04$ \\
\hline Soebe & $52.033 .106,21$ & 68 & $765.192,74$ \\
\hline
\end{tabular}

(continua) 
Tabela 1

Maiores Vencedores de Contratos da SVP (continuação)

\begin{tabular}{l|c|c|c}
\hline Vencedor & $\begin{array}{c}\text { Valor Total } \\
\text { (em R\$ de } \\
12 / 1999)\end{array}$ & $\begin{array}{c}\text { No de } \\
\text { Contratos }\end{array}$ & $\begin{array}{c}\text { Valor Médio } \\
\text { (em R\$ de } \\
12 / 1999)\end{array}$ \\
\hline CMTC & $49.235 .825,65$ & 1 & $49.235 .825,65$ \\
Telar & $48.814 .183,57$ & 36 & $1.355 .949,54$ \\
Soempa & $46.508 .403,46$ & 64 & $726.693,80$ \\
\hline Total das 40 maiores & $\mathbf{7 . 1 9 7 . 2 9 4 . 6 3 7 , 9 4}$ & $\mathbf{2 . 1 3 3}$ & $\mathbf{3 . 3 7 4 . 2 5 9 , 0 8}$ \\
\hline Total de todas as empresas & $\mathbf{8 . 5 9 1 . 1 8 5 . 7 8 6 , 8 1}$ & $\mathbf{4 . 9 2 9}$ & $\mathbf{1 . 7 4 2 . 9 8 7 , 5 8}$ \\
\hline
\end{tabular}

Fonte: Diário Oficial do Município de São Paulo.

a realização de grandes obras, com grande impacto sobre a cidade de São Paulo, como a construção da Avenida Jacú-Pêssego (CR Almeida e Cowan), o túnel sob o Rio Pinheiros (Camargo Corrêa) e o minianel viário (Andrade Gutierrez). Esses dados reforçam a impressão de que a EMURB foi sempre utilizada para a realização das maiores obras, que necessitavam de agilidade operacional, através de empresas de grande porte, típicas do mercado de obras públicas nacional. Essas empresas efetuaram contratos geralmente em administrações de direita, mais especificamente nos governos Jânio Quadros, Paulo Maluf e Celso Pitta.

As duas outras empresas que figuram entre as dez maiores vencedoras em todo o período, a Serveng Civilsan (SP) e a Firpavi (SP), apresentam um padrão distinto de vitórias e típico das empresas do setor. Elas venceram vários contratos com a Secretaria, dispersos ao longo do tempo, para a realização de obras menores e mais espalhadas pela cidade. A Serveng Civilsan, vencedora de contratos em várias administrações, realizou inúmeras pequenas obras de pavimentação em diversos locais da cidade, além de pequenos trabalhos de drenagem e contenção de taludes, ao lado de outros de maior porte, como as canalizações dos córregos Pirajussara e Jaguaré. Já a Firpavi, contratada em vários governos, realizou especialmente pavimentações encomendadas por diferentes Administrações Regionais do Município de São Paulo, além de algumas obras de drenagem, especialmente construção e reforma de galerias de águas pluviais.

As demais empresas da Tabela 1 seguem esse padrão disperso ao longo do tempo, com muitos contratos de valor não muito elevado, à exceção de duas que vencem menos de dez contratos, com elevados va- 
lores médios - Construbase e Imobel. As firmas que vencem de forma contínua ao longo do período são consideradas por nós como típicas do setor de obras públicas locais. Embora elas não tenham capital muito elevado, nem estejam próximas do núcleo de poder institucional, são essas empresas que possuem a maior quantidade de vínculos e uma presença mais constante nas redes da comunidade, estando ligadas principalmente a técnicos e indivíduos pertencentes à burocracia do setor.

Podemos ainda destacar os locais de origem das empresas que mais venceram, o que auxilia na compreensão da dinâmica do mercado de obras públicas em São Paulo. Do início do período em estudo até a administração Jânio Quadros, observa-se a presença quase exclusiva de firmas paulistas nas contratações, seguidas das mineiras, que ganham menos proporcionalmente, conforme pode ser observado na Tabela 2. Este conjunto de empresas apresenta pequeno porte e detém pequeno capital médio, o que faz com que, no início do período analisado, as empresas locais e mais especializadas vencessem a maior parte dos contratos. Somente nas administrações Jânio Quadros, Paulo Maluf e Celso Pitta empresas de outros estados vencem contratos, especialmente as mineiras, baianas e cariocas, de maior porte e capital médio, confirmando uma invasão no setor local de infra-estrutura viária por empresas nacionais a partir da segunda metade dos anos 80. Essas maiores são exatamente aquelas contratadas pela EMURB para a realização das obras de grande impacto sobre a cidade.

Tabela 2

Proporção de Vitórias das Maiores Vencedoras por Estados-Sedes e Governo

\begin{tabular}{l|c|c|c|c|c|c}
\hline \multirow{2}{*}{ Governos } & \multicolumn{7}{|c}{ Estados-Sedes das Empresas } \\
\cline { 2 - 7 } & Bahia & Goiás & Minas Gerais & Rio de Janeiro & São Paulo & Total \\
\hline Setúbal & 0,00 & 0,00 & 3,18 & 0,00 & 96,82 & 100,00 \\
Reynaldo & 0,00 & 0,00 & 1,96 & 0,00 & 98,04 & 100,00 \\
Curiati & 0,00 & 0,00 & 0,00 & 0,00 & 100,00 & 100,00 \\
Covas & 0,00 & 0,00 & 4,24 & 0,00 & 95,76 & 100,00 \\
Jânio & 0,00 & 0,00 & 32,71 & 20,88 & 46,41 & 100,00 \\
Erundina & 0,00 & 0,00 & 27,38 & 0,00 & 72,62 & 100,00 \\
Maluf & 15,63 & 1,14 & 27,82 & 7,26 & 48,16 & 100,00 \\
Pitta & 41,02 & 0,94 & 13,62 & 4,73 & 39,70 & 100,00 \\
\hline Total & $\mathbf{7 , 4 2}$ & $\mathbf{0 , 4 1}$ & $\mathbf{2 2 , 7 7}$ & $\mathbf{1 0 , 3 6}$ & $\mathbf{5 9 , 0 4}$ & $\mathbf{1 0 0 , 0 0}$ \\
\hline
\end{tabular}

Fontes: Diário Oficial do Município de São Paulo e Junta Comercial do Estado de São Paulo. 
Gráfico 4

Capital Médio das Vinte Maiores Vencedoras

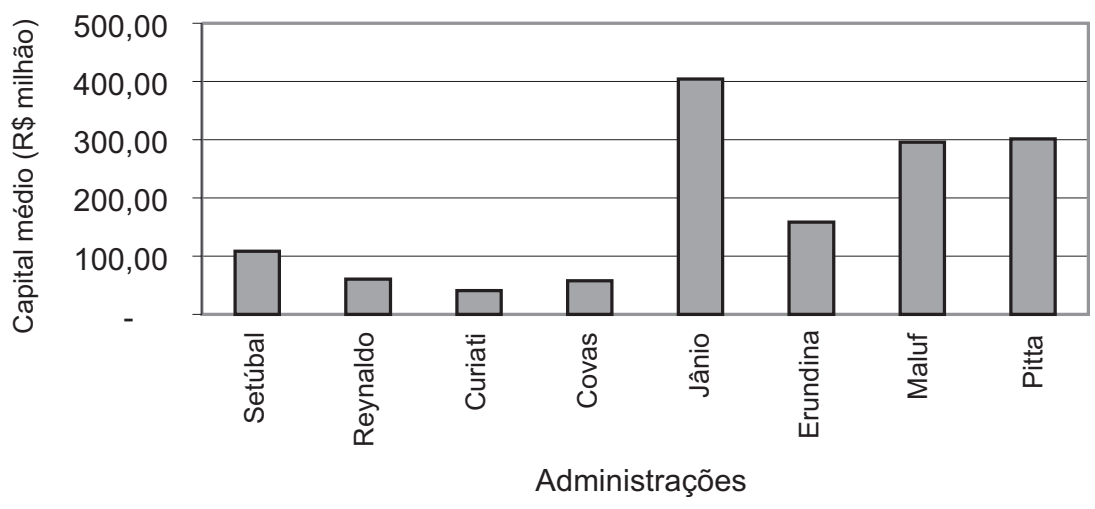

Fonte: Diário Oficial do Município de São Paulo.

O Gráfico 4 complementa essa informação, indicando a elevação abrupta do capital médio das empresas vencedoras a partir da administração Jânio Quadros, com uma ligeira redução na administração Luiza Erundina, e novas elevações nas administrações Paulo Maluf e Celso Pitta.

\section{A rede da comunidade}

Além da pesquisa primária relativa às contratações da Secretaria já referida, realizamos uma série de entrevistas com técnicos do setor. Nestas foram explorados os vínculos entre indivíduos, grupos e empresas de forma a permitir a reconstituição das redes de relações por governo ${ }^{14}$. Tais redes são representáveis através de visualizações como sociogramas e escalas, além de passíveis de análise quantitativa com estatísticas próprias. A análise que se segue explora essa rede de maneira a verificar a influência de posições e padrões de vínculo nas vitórias de empresas em licitações.

A Figura 1 apresenta o sociograma da rede da comunidade centrada na SVP durante o governo Reynaldo de Barros. Na figura, os círculos representam indivíduos da comunidade e os traços denotam as ligações entre os indivíduos, sendo que a sua espessura corresponde à 
Figura 1

Rede de Relações da Comunidade no Governo Reynaldo de Barros

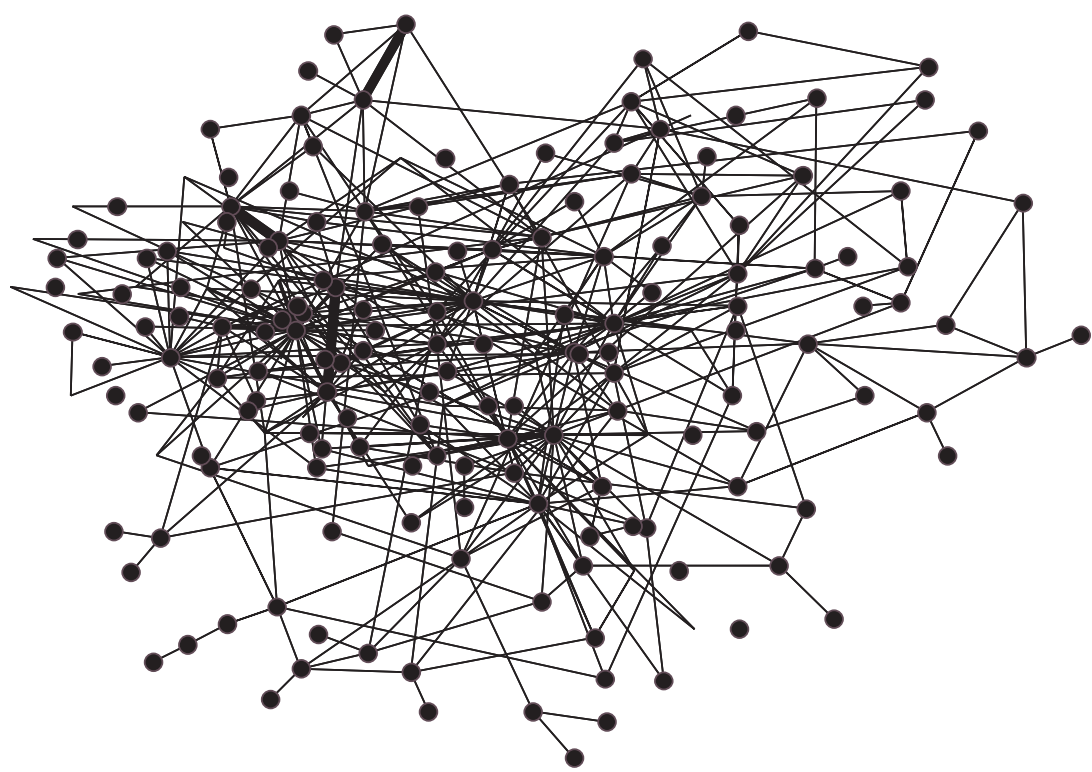

Fonte: Entrevistas com membros da comunidade.

força dos vínculos ${ }^{15}$. Dado que a quantidade de nós e relações se adensa nas administrações subseqüentes, não apresentaremos aqui os sociogramas dos demais governos, uma vez que a visualização destes ficaria prejudicada. Assim, todos os resultados apresentados nesta seção se baseiam em análises estatísticas, e não em sociogramas ou outras formas de visualização, sendo a Figura 1 apresentada apenas com fins ilustrativos.

Para analisarmos a influência do padrão de relacionamento no interior da rede sobre o padrão de vitória das empreiteiras, somamos os valores ganhos por cada empresa ao longo de cada governo e comparamos estes valores, em termos estatísticos, com um conjunto de variáveis, diversas delas calculadas a partir das redes de cada administração ${ }^{16}$.

Como o número de empresas distintas que ganham por governo é muito grande, mas a maior parte vence uma proporção muito reduzida do total licitado, restringimos a análise às empresas com um total de vitórias superior a $R \$ 20$ milhões ou com mais de vinte contratos, o 
que nos deixou com um universo de 183 casos (empresas/governo). Para onze empresas/governo, não obtivemos informação de capital, e para 31, não conseguimos informações que nos permitissem ligá-las à rede, considerando todas as suas estatísticas da rede iguais a zero ${ }^{17}$. A variável dependente da análise, portanto, é o valor total de contratos de cada uma das maiores vencedoras em cada governo.

Tentamos submeter a exame uma série de variáveis que pudessem testar a importância de diferentes fenômenos no funcionamento da permeabilidade do Estado. Incluímos, primeiramente, uma variável relacionada à escala econômica da empresa - o capital -, segundo os capitais registrados na Junta Comercial do Estado de São Paulo, de forma a testar a importância do poder econômico no padrão de intermediação de interesses presente na política. Em segundo lugar, introduzimos a variável da inclinação político-ideológica do prefeito, de forma a testar a existência de padrões diferenciados de permeabilidade entre esquerda e direita, assim como a influência do ambiente político sobre as vitórias.

Além dessas, incluímos a quantidade de licitações por governo, medida pelo número médio por governo de contratos licitados por ano, de forma a controlar o volume de vitórias pela oferta diferenciada de licitações por governo, do mesmo modo que uma variável relativa à concentração de vitórias das licitações em cada governo, medida pela média em cada governo dos contratos por vencedor e ano.

Por fim, construímos variáveis associadas especificamente às redes, por governo, descritas em detalhes a seguir. Essas variáveis foram tratadas estatisticamente de duas formas: um primeiro conjunto foi calculado reconstruindo as redes com indivíduos e empresas privadas; um outro a partir das redes com os indivíduos previamente aglutinados em grupos, cada um deles com intensos vínculos internos e padrões similares de vínculos com outros grupos ${ }^{18}$.

As variáveis relacionais incluíram inicialmente cinco estatísticas de centralidade na rede - o grau (que mede a quantidade de vínculos primários de um certo nó); o poder (que mede a quantidade de vínculos primários e secundários de um determinado nó ${ }^{19}$ ); a proximidade (medida sintética que indica a proximidade de um dado nó a todos os outros da rede); a intermediação (que indica quantos caminhos passam necessariamente por um dado nó, dentre todos os caminhos na 
rede); e a informação (que mede quantos caminhos passam por um dado nó, sendo o caminho único ou não, dentre todos os caminhos da rede). O objetivo do cálculo dessas variáveis era testar os diferentes efeitos da presença do chamado poder posicional (Marques, 2000) um tipo de poder derivado da ocupação de posições na rede e da propriedade de padrões de vínculos específicos -, que é negociado por empresas, indivíduos e grupos burocráticos com os detentores do poder institucional, oriundo da investidura de cargo e do poder econômico no desenrolar da política pública.

Além dessas informações relacionais, utilizamos variáveis extraídas da rede, mas que apontam para características de proximidade direta com o núcleo do poder institucional na política de cada governo - distância em passos do prefeito, do secretário de Obras, do chefe de gabinete, do superintendente de obras e do superintendente de projetos, todas medidas pelo menor caminho na rede daquele governo ${ }^{20}$.

Análises de correlação simples indicaram que uma grande quantidade dessas variáveis não se apresentava nem mesmo correlacionada com o volume de vitórias por empresa e administração. Todas foram retiradas da análise ${ }^{21}$. Em primeiro lugar, foram excluídas as variáveis relacionais calculadas a partir das redes de indivíduos e empresas que não apresentaram nenhuma significância na explicação do volume de recursos ganhos por empresa e administração ${ }^{22}$.

Dentre as variáveis relacionais (todas calculadas a partir das redes de grupos e empresas), proximidade, informação e intermediação não apresentaram significância e também foram abandonadas. Submetidas à análise semelhante, todas as variáveis de distância de ocupantes de cargos demonstraram ser relevantes. Entretanto, como todas as distâncias se mostraram correlacionadas, optamos por manter a distância do prefeito, menos correlacionada com as demais variáveis da análise multivariada (ver a seguir) ${ }^{23}$. Por fim, as variáveis relativas à concentração de vitórias apresentaram correlação estatisticamente significativa com o volume de recursos ganho por governo, e sinal negativo, indicando que em anos de elevado número de contratos os valores ganhos pelas empresas tendem a ser menores. Entretanto, essas variáveis são correlacionadas com diversas outras da análise multivariada, o que nos fez abandoná-las. 
Assim, apresentaram correlação com o volume de vitórias por governo e empresa e foram introduzidas na análise multivariada as seguintes variáveis: se o governo era de direita ou de esquerda; o capital da empresa; a distância do prefeito de cada empresa na rede; o grau de cada empresa (a quantidade de vínculos primários); e o poder de cada empresa (a quantidade de vínculos primários e secundários) ${ }^{24}$. A Tabela 3 apresenta os resultados dos coeficientes e as significâncias da explicação do padrão de distribuição de recursos por empresas em cada governo ${ }^{25}$.

Tabela 3

Coeficientes de Regressão - Universo das Empresas

\begin{tabular}{|c|c|c|c|c|c|}
\hline & $\begin{array}{l}\text { Coeficientes } \\
\text { Não Padroni- } \\
\text { zados }\end{array}$ & & $\begin{array}{c}\text { Coeficientes } \\
\text { Padroniza- } \\
\text { dos }\end{array}$ & Estatística t & Signif. \\
\hline & B & $\begin{array}{l}\text { Desvio- } \\
\text { Padrão }\end{array}$ & Beta & & \\
\hline Constante & 15,443 & 0,252 & & 61,294 & 0,000 \\
\hline $\begin{array}{l}\text { Dummy para gover- } \\
\text { nos de direita }\end{array}$ & 1,944 & 0,144 & 0,642 & 13,521 & 0,000 \\
\hline Capital & 0,00000000142 & 0,000 & 0,339 & 8,097 & 0,000 \\
\hline $\begin{array}{l}\text { Grau (vínculos pri- } \\
\text { mários) }\end{array}$ & 0,0653 & 0,033 & 0,093 & 1,987 & 0,049 \\
\hline $\begin{array}{l}\text { Poder (vínculos pri- } \\
\text { mários e secundá- } \\
\text { rios) }\end{array}$ & 0,042 & 0,014 & 0,125 & 2,918 & 0,004 \\
\hline Distância do prefeito & $-0,117$ & 0,044 & $-0,136$ & $-2,679$ & 0,008 \\
\hline
\end{tabular}

Obs.: Variável dependente transformada (log neperiano do volume total).

Como podemos ver, apresentaram significância estatística e coeficientes positivos as variáveis inclinação ideológica do prefeito, capital das empresas e as quantidades de vínculos primários e secundários de cada empresa em cada governo. Além destas, tem significância a distância que separa cada empresa do prefeito, em cada governo, mas o sinal, neste caso, é negativo. Este resultado era previsto, pois conceitualmente estamos testando a importância da proximidade, e a variável mede o seu inverso (a distância): quanto maior a distância (e menor a proximidade), menor o volume de recursos ganhos por uma dada empresa. 
O primeiro elemento a destacar é a relevância da inclinação ideológica do prefeito, que não se refere a um atributo das empresas, mas introduz o ambiente político no estabelecimento do padrão de vitórias. Isso indica que a permeabilidade e o padrão de intermediação de interesses diferem entre empresas que se encontram em um governo de direita ou de esquerda. Como já afirmamos anteriormente, esse elemento apresenta uma grande capacidade explicativa nas mais variadas dimensões da política estudada, sugerindo que as características das políticas de governos de direita e de esquerda encontradas por nós expressam, na verdade, as preferências de políticas dos governantes em São Paulo, em especial de direita, durante o período em tela ${ }^{26}$. Assim, se empresas em completa igualdade de condições (com o mesmo capital, os mesmos vínculos e posição na rede) estão presentes em um governo de esquerda e outro de direita, há uma tendência de o valor das vitórias no governo de direita ser significativamente superior ${ }^{27}$. Mais adiante, analisaremos o padrão de vitórias em governos de esquerda e de direita separadamente, tentando determinar como funciona cada padrão de intermediação.

Observemos agora o impacto dos atributos das empresas e de suas relações sobre os padrões de vitória. Em primeiro lugar, apresentou relevância o capital das empresas, indicando que nas obras de infra-estrutura urbana em São Paulo, em período recente, o poder econômico e a escala das empresas são importantes para a explicação do volume de vitórias obtido por elas. Vale destacar que, no caso das políticas de saneamento no Rio de Janeiro (ver Marques, 1999a; 2000), os capitais das empresas não eram relevantes para a explicação do conjunto das vitórias, embora o fossem para as obras de valor mais elevado executadas no final do período. Voltaremos a este ponto mais adiante.

Três variáveis relacionais apresentaram significância - quanto mais vínculos primários e secundários uma empresa tiver, assim como quanto mais próximas do núcleo do poder institucional as empresas estiverem, maiores serão seus volumes de vitórias. Isto indica que tanto o poder posicional quanto o acesso ao poder institucional são importantes para as empresas no mercado de infra-estrutura em São Paulo, e quanto mais vínculos uma empresa tiver e mais próxima estiver do prefeito na rede ${ }^{28}$, maior tenderá a ser o seu volume de contratos. Vale observar que, embora estejamos tratando com duas variáveis relacionais, estas apresentam relações diferentes com a rede. 
O poder posicional, ao contrário do acesso ao poder institucional, está muito mais ligado à história da rede e a um conjunto significativo de vínculos mais antigos e não intencionais. O mesmo pode ser dito dentre as medidas de poder posicional: das duas variáveis de quantidade de vínculos, a relacionada com vínculos primários (grau) apresenta-se mais associada à história da rede, a vínculos não intencionais e antigos, enquanto a relacionada com vínculos secundários pode dizer respeito (embora não na maior parte das vezes) ao estabelecimento de vínculos intencionais com indivíduos e grupos de grande centralidade.

Esse resultado novamente distancia o caso aqui estudado daquele tratado em Marques (2000), já que na experiência carioca os vínculos primários eram importantes, mas estavam acompanhados de uma outra medida relacional - a informação - que no caso paulistano não apresentou significância estatística. Além disso, no caso carioca, a proximidade dos detentores de poder institucional era importante apenas para empresas de grande porte.

Mas será que, considerando a importância da inclinação ideológica do prefeito não apenas aqui, mas em toda a pesquisa, esse padrão geral é composto por padrões diferentes em governos de esquerda e de direita? Como o número de casos é razoável, dividimos o banco de dados e testamos as mesmas variáveis para governos de direita e de esquerda, separadamente.

Quando distinguimos vitórias em governos de direita, quase todas as variáveis anteriores permanecem significativas - capital, distância do prefeito e vínculos secundários. Os vínculos primários não mais apresentaram significância, e a inclinação ideológica foi retirada do modelo por motivos óbvios. A Tabela 4 apresenta os resultados ${ }^{29}$.

Por outro lado, quando analisamos apenas governos de esquerda, encontramos um padrão bastante diferente dos anteriores, como podemos ver na Tabela $5^{30}$. A única variável que continua a apresentar correlação significativa é o capital. Isto indica, em primeiro lugar, que, em governos de esquerda, o poder posicional (vínculos primários e secundários) e a proximidade dos detentores do poder institucional (sejam eles prefeitos, secretários ou superintendentes) não influenciam na construção dos padrões de vitória de empreiteiras em obras de infra-estrutura urbana em São Paulo em período recente. Como essa comunidade de política é tradicionalmente associada com a direita, e 
Tabela 4

Coeficientes de Regressão - Governos de Direita

\begin{tabular}{l|c|c|c|c|c}
\hline & $\begin{array}{c}\text { Coeficientes Não } \\
\text { Padronizados }\end{array}$ & B & $\begin{array}{c}\text { Coeficien- } \\
\text { tes Padro- } \\
\text { nizados }\end{array}$ & $\begin{array}{c}\text { Estatís- } \\
\text { tica t } \\
\text { Padrão }\end{array}$ & Signif. \\
\cline { 2 - 5 } & 18,263 & 0,248 & & 73,583 & 0,000 \\
\hline Constante & 0,000000000954 & 0,000 & 0,386 & 4,305 & 0,000 \\
Capital (da Junta Comercial) & $-0,331$ & 0,079 & $-0,376$ & $-4,173$ & 0,000 \\
$\begin{array}{l}\text { Distância em passos do pre- } \\
\text { feito 1 }\end{array}$ & 0,056 & 0,016 & 0,308 & 3,441 & 0,001 \\
\hline
\end{tabular}

Obs.: Variável dependente transformada (log neperiano do volume total).

foi estruturada ao longo de seus governos, podemos interpretar esse resultado como um aparente sucesso dos governos de esquerda na neutralização da influência da rede nos processos de licitação. Em segundo lugar, entretanto, os resultados apontam que, também em governos de esquerda, o poder econômico e/ou o porte das empresas são importantes na definição do volume de vitórias das empreiteiras. De fato, o valor dos coeficientes da variável capital nas duas regressões sugere que o efeito do poder econômico seja similar, mas levemente mais elevado em governos de esquerda do que de direita.

Tabela 5

Coeficientes de Regressão - Governos de Esquerda

\begin{tabular}{|c|c|c|c|c|c|}
\hline & $\begin{array}{c}\text { Coeficientes } \\
\text { Não Padroni- } \\
\text { zados }\end{array}$ & & $\begin{array}{c}\text { Coeficientes } \\
\text { Padroniza- } \\
\text { dos }\end{array}$ & Estatística t & \multirow[t]{2}{*}{ Signif. } \\
\hline & B & $\begin{array}{l}\text { Desvio- } \\
\text { Padrão }\end{array}$ & Beta & & \\
\hline Constante & 15,027 & 0,088 & & 169,976 & 0,000 \\
\hline $\begin{array}{l}\text { Capital (da Junta } \\
\text { Comercial) }\end{array}$ & 0,00000000137 & 0,000 & 0,461 & 4,159 & 0,000 \\
\hline
\end{tabular}

Obs.: Variável dependente transformada (log neperiano do volume total). 
Na política de saneamento do Rio de Janeiro, empresas de grande capital apresentavam um padrão de intermediação e permeabilidade diferente das empresas de pouco capital. Com relação à SVP, podemos afirmar que o capital tende a ser maior entre os vencedores de governos de direita ${ }^{31}$, e que as empresas de grande capital tendem a localizar-se mais próximas do secretário de Vias Públicas ${ }^{32}$. Como a distância do secretário, para uma dada empresa, tende a ser menor em governos de direita, testamos se a correlação entre capital e distância do secretário persiste quando controlada por governos de direita / esquerda. Os resultados mantêm-se quase sem alteração ${ }^{33}$, indicando que empresas de capital elevado tendem a localizar-se mais próximas ao núcleo do poder institucional da política em todas as administrações, mas que em governos de direita essa distância tende a ser menor ainda.

\section{CONCLUSÃO}

$\mathrm{O}$ artigo apresenta os resultados de uma pesquisa que tenta explicar os padrões de vitória de empreiteiras em uma dada política pública urbana a partir das redes de relações que ligam técnicos e burocratas, membros da classe política e empreiteiras no interior de uma comunidade profissional.

Os resultados indicam, em primeiro lugar, que as vitórias tendem a se concentrar em poucas empresas, que os mais importantes vencedores tendem a ter uma parcela dos recursos garantida, que empresas de grande porte, principalmente, se fizeram presentes no mercado local de obras públicas em anos recentes, e que o padrão de concentração, apesar de recentemente ter se elevado em termos de valores ganhos, sofre uma importante influência do quadro legal que regula as licitações.

Além disso, partindo da reconstituição das redes de relações da comunidade de política por governo, o artigo mostra que o volume de vitórias das grandes empreiteiras em licitações tende a ser maior em governos de direita, assim como tende a ser maior o número de vitórias das empresas de maior capital. As posições das empresas na rede também influenciam seus volumes de vitórias e empresas com mais vínculos primários e secundários, mais próximas do prefeito e do secretário de Vias Públicas, tendem a obter volumes mais elevados de recursos. Esse efeito se mantém praticamente idêntico quando 
analisamos isoladamente os governos de direita, mas em governos de esquerda a única variável que tende a influenciar positivamente o volume de vitórias é o capital das empresas.

Em termos mais analíticos, a permeabilidade do Estado presente nas políticas da SVP de São Paulo está baseada em três tipos de poder econômico, posicional e institucional (ver Marques, 2000). Para o conjunto dos governos assim como para governos de direita, as empresas que dispõem desses três poderes tendem a vencer mais. Em governos de esquerda, os poderes institucional e posicional não explicam o padrão de vitória. Aparentemente, os governos de esquerda do período foram bem-sucedidos não só em vetar o acesso das empresas ao poder institucional (como apresentado no discurso "nativo" dessas administrações), como também em neutralizar o efeito do poder posicional da rede da política, muito fortemente associada às administrações de direita e a seus gestores. O artigo confirma, portanto, a importância da clivagem esquerda / direita para a definição dos conteúdos das políticas, já destacada em Marques e Bichir (2001a), assim como dos procedimentos para sua implementação. Parte da explicação das diferenças na permeabilidade do Estado, por conseguinte, é originária do campo político. Vale destacar, entretanto, que mesmo quando a rede influencia o volume de vitórias - para as empresas vencedoras em governos de direita -, as variáveis relacionais que se mostraram importantes não são portadoras da história e da estrutura da rede, no sentido da permeabilidade conceituada em Marques (2000) ${ }^{34}$.

Em termos comparativos, a rede, entendida como estruturação do conjunto de vínculos de inúmeros tipos estabelecido ao longo da vida dos indivíduos e das organizações, é menos central na permeabilidade da SVP do que se havia mostrado no caso da CEDAE. Na política de saneamento carioca, o padrão de vitórias não dependia do poder econômico, nem do poder institucional, mas de determinadas formas de poder posicional. Apenas para as empresas de grande porte que "invadiram" o mercado local a partir do final dos anos 80 , o poder institucional importava.

Com base na comparação com esse padrão carioca, gostaríamos de acrescentar um elemento institucional na explicação da permeabilidade, já presente, mas muito pouco explícito, em Marques (idem). As informações apresentadas aqui indicam que agências de tipos diferentes geram (e, em parte, são geradas por) redes de tipos e caracterís- 


\section{Eduardo Cesar Marques e Renata Mirandola Bichir}

ticas distintos. Além disso, entretanto, a importância das redes de relações (e do poder posicional) no desenrolar da política parece ser muito distinta em agências com desenhos diferentes. Embora o número de estudos sobre organizações e redes ainda seja pequeno, tudo indica que em uma agência insulada e horizontalizada como a CEDAE, tanto políticos quanto empresas privadas necessitam adquirir poder posicional para chegar a seus objetivos - administrar e ganhar contratos. A importância atribuída ao poder posicional nesse caso é elevada, fato que se expressa inclusive no status da burocracia. Em uma agência pouco institucionalizada e escassamente insulada como a SVP, a importância dos vínculos construídos paulatinamente e da estrutura da rede é muito menor e, portanto, o valor das posições é muito mais baixo. Em um caso como este, a permeabilidade está associada quase que exclusivamente aos poderes econômico e institucional, assim como a dinâmicas relacionais derivadas destes.

(Recebido para publicação em agosto de 2002)

(Versão definitiva em dezembro de 2002)

\section{NOTAS}

1. Para um exemplo, ver Fiori (1995).

2. O exemplo mais claro disto está na constituição, em período recente, de agências regulatórias federais de políticas setoriais, a partir das burocracias técnicas das empresas estatais que estruturavam as políticas anteriormente. Como os técnicos transferidos quase certamente transportaram com eles os seus vínculos com as redes dos setores, o padrão de intermediação de interesses anterior certamente sobreviverá, embora adaptado aos novos formatos das instituições (Marques, 1999b).

3. Vale destacar que, em ambos os casos, estamos falando de fenômenos relacionais veiculados pelas redes. A questão é que padrão de relações é mais relevante para explicar a permeabilidade.

4. Para uma comparação entre ambas, ver Meirelles (1995) e Amaral (1995).

5. Ver, p. ex., O Estado de S. Paulo, 28/2/2002, 15/3/2002 e 27/3/2002; Folha de S. Paulo, 10/6/2001,8/1/2002,31/1/2002,1/2/2002 e 3/2/2002.

6. Esta é a data de referência da pesquisa (e deste artigo), para a qual foram transportados todos os valores, depois de convertidos e atualizados financeiramente, utilizando os valores do índice IGP-DI, elaborado pela Fundação Getulio Vargas. 
7. No início da pesquisa foram considerados de "direita" os prefeitos pertencentes ao partido que apoiou a ditadura militar instaurada em $1964 \mathrm{e}$ aos partidos dele oriundos: Olavo Setúbal (ArenA), Reynaldo de Barros (ARENA), Salim Curitati (PDS), Jânio Quadros (PTB), Paulo Maluf (PPB) e Celso Pitta (PTN). De modo similar, foram considerados "não de direita" os prefeitos pertencentes ao partido de oposição e seus descendentes após a abertura política (Mário Covas e Luiza Erundina, do PMDB e do PT, respectivamente). Durante o desenrolar da pesquisa, o conteúdo das políticas de cada administrador foi sendo esclarecido, o que nos deu segurança para denominar de "esquerda" os administradores Mário Covas e Luiza Erundina por estes apresentarem políticas voltadas para questões de justiça social, visando à redução das desigualdades (cf. a distinção entre "direita" e "esquerda" empreendida por Bobbio, 2001).

8. Estipulado em $25 \%$ do valor original do contrato, tanto pelo Decreto-Lei $\mathrm{n}^{-}$ 2.300/86 quanto pela Lei no 8.666/93.

9. A fim de caracterizar espacialmente a distribuição dos investimentos da SVP, foi construída uma base espacial que agregou as extensões do Município de São Paulo, a partir de seus conteúdos socioeconômicos, evitando assim a utilização de modelos espaciais preconcebidos. Os procedimentos desenvolvidos para a construção da base espacial, os grupos sociais dela resultantes, bem como uma discussão aprofundada sobre as características da segregação socioespacial em São Paulo são apresentados em Marques e Bichir (2001b; 2001c, este último com especial enfoque sobre as periferias metropolitanas).

10. Como veremos mais adiante com maior grau de detalhe, a partir da realização de entrevistas com técnicos do setor, recompusemos as redes de relações entre indivíduos, grupos e empresas privadas no interior da comunidade da política por administração municipal. A partir dessas redes, calculamos as distâncias médias do conjunto das empresas ao prefeito e ao secretário de Vias Públicas em cada governo, assim como o conjunto médio de vínculos primários (medidos pela estatística "Degree") e secundários (medidos pela estatística "Power") das empresas por administração. Tomamos essas três variáveis como representativas da presença do "mundo das empresas" na política, assim como da sua proximidade do núcleo do poder executivo na Secretaria. Todas as três são correlacionadas com o volume anual de investimentos, a primeira negativamente (já que mede distância, o inverso da proximidade) e as seguintes positivamente. Para uma análise quantitativa, ver Marques e Bichir (2001a; 2001b) e para maiores detalhes de método e técnica, ver Marques (2000) e Wasserman e Faust (1994).

11. A lista da tabela é apenas ilustrativa. Os maiores vencedores que foram trabalhados nas entrevistas e na análise quantitativa que se segue foram delimitados a partir da associação de dois critérios de seleção: empresas que obtiveram um total igual ou superior a R $\$ 20$ milhões (independentemente do número de contratos), e também empresas que venceram vinte ou mais licitações (independentemente do seu valor total), formando um total de 88 empresas que foram analisadas mais detalhadamente. Com esses critérios, pretendemos incluir empresas com grande volume de vitórias, mas também aquelas de valores mais baixos que tenham vencido muito, incluindo mais empresas do que as apresentadas na Tabela 1. 


\section{Eduardo Cesar Marques e Renata Mirandola Bichir}

12. Após o nome da empresa aparece entre parênteses o estado de origem/sede da mesma.

13. Não por acaso, dentre estas, a C. R. Almeida, Camargo Corrêa, Andrade Gutierrez e Constran situavam-se, em 1999, entre as oito maiores empresas de construção do país, incluídas na lista das quinhentas maiores empresas brasileiras da revista Exame. Uma quinta empresa, a CBPO, não constava da lista, mas a sua controladora, a Odebrecht, sim (revista Exame, Melhores e Maiores, junho de 2000).

14. Em termos de operacionalização, foram realizadas inúmeras entrevistas com indivíduos que participam da comunidade de políticas estudada, ao longo das quais instamos os entrevistados a relacionar nomes de pessoas e empresas a uma lista de nomes preparada previamente pelo entrevistador. Em outras entrevistas, foram explorados os tipos de vínculo e os momentos de constituição das ligações citadas. Uma técnica estatística própria permitiu reproduzir a estrutura da rede, representá-la através de gráficos e analisar as posições ocupadas pelos diversos indivíduos, seus grupos e a estrutura geral da rede. Para a metodologia aplicada aqui, ver Marques (2000, Anexo 3), e para a metodologia em seus aspectos mais gerais, ver Scott (1992) e Wasserman e Faust (1994). Sobre visualizações de redes, ver Freeman et alii (1998).

15. O sociograma compreende apenas indivíduos, já que a inclusão das empresas tornaria a visualização ainda mais difícil. Estão abrangidos todos os tipos de vínculos já processados, seguindo os passos metodológicos de Marques (2000). A força dos vínculos expressa a freqüência de citações da relação nas entrevistas.

16. Considerando a não-linearidade dos volumes de vitórias, utilizamos uma transformação logarítmica (neperiana) na variável dependente - volume total de vitórias na administração. Todos os resultados discutidos a seguir dizem respeito à variável dependente transformada, exceto quando indicado em contrário.

17. Duas empresas muito citadas em entrevistas foram mantidas na análise apesar de não obedecerem a esses critérios.

18. Os grupos foram construídos mediante a aplicação de análise de agrupamento às matrizes de relações entre indivíduos e empresas por administração, o que gerou agrupamentos de indivíduos com padrões similares de inserção na rede.

19. Nesse caso, há um "desconto" para o fato de o vínculo ser secundário: somam-se os primários aos secundários, reduzidos por uma "taxa de desconto" beta. Testamos com beta de $90 \%$ e $75 \%$, o que quer dizer que um dado nó recebe como atributo todos os seus vínculos primários mais os secundários multiplicados por 0,9 ou 0,75, respectivamente.

20. Nos casos em que mais de um indivíduo ocupou esses cargos, testamos para cada um deles separadamente. Quando não tínhamos o cargo ligado à empresa alguma durante um dado governo, consideramos a maior distância possível na rede, naquele governo. Ainda sobre as distâncias de ocupantes de cargos, testamos também filtrar a variável pelo pertencimento ou não do indivíduo à comunidade, mas os resultados não foram nada promissores e foram abandonados, já que quando controlamos pela inclinação ideológica do prefeito, o pertencimento à comunidade deixou de ter qualquer relevância. 
21. Mais adiante, essas variáveis foram introduzidas nos modelos multivariados de maneira a testar a possibilidade de não apresentarem correlação direta com a variável dependente pela presença de variáveis intervenientes, mas os resultados não acrescentaram nada ao que a análise multivariada já apontava.

22. Esse resultado confirma o encontrado em Marques (2000), que já havia levantado a hipótese de a importância das relações das empresas estar no relacionamento com grupos no interior da comunidade, e não com indivíduos (sendo estes os suportes das relações com os primeiros).

23. Uma análise fatorial indicou que um único elemento explica $86 \%$ da variância total. A correlação entre prefeito e secretário é de 0,76, significativa a $99 \%$.

24. Ambas as variáveis de poder se apresentaram correlacionadas com as vitórias, mas o poder com beta de 0,75 manteve-se na análise multivariada, ao contrário do poder com 0,9, mais correlacionado com as demais variáveis independentes.

25. O modelo apresenta aderência muito boa, seja medida pelo R2 igual a 0,742, seja pela estatística $F$ relativa aos resíduos, igual a 88,230, significativa a 99\%. Caso não tivéssemos considerado as estatísticas das empresas não ligadas à rede como iguais a zero, a aderência seria ainda melhor, mas nenhuma nova variável independente se apresentaria significativa. Vale acrescentar que um único caso desviante foi retirado da análise: a empresa Andrade Gutierrez durante o governo Pitta, cujo volume de vitórias se situou mais de três desvios-padrão abaixo do previsto pelo modelo.

26. Este resultado não foi encontrado em Marques (1999a; 2000) para as licitações de obras e serviços de saneamento no Rio de Janeiro em período similar.

27. Vale observar que este resultado poderia ser explicado pelo fato de os governos de direita licitarem mais e gastarem totais anuais mais elevados que governos de esquerda. Para controlar tal efeito, experimentamos introduzir o contrato médio por governo, assim como o valor total gasto neste. A primeira variável apresenta correlação com o volume de vitórias por governo, mas quando controlamos por direita/ esquerda (já que em governos de direita o contrato médio tende a ser mais alto), o efeito desaparece. A variável "total gasto", entretanto, continua correlacionada, mesmo controlando por direita/esquerda, o que indica que, independentemente da inclinação política do prefeito, quando o volume geral de contratos é mais elevado, as empresas tendem a vencer volumes mais elevados, o que, além de intuitivo, é compatível com a discussão da concentração de vitórias apresentada anteriormente, em especial nossa interpretação do Gráfico 2.

28. Assim como ao secretário.

29. A regressão envolveu 92 casos, alcançando R2 de 0,44 e estatística F de 23,7 (significativa a 99\%). Nesse modelo, assim como no que se segue, a variância explicada cai muito em relação ao modelo original, principalmente pela retirada da inclinação ideológica.

30. O número de casos é de 65, sendo o R2 igual a 0,213 e a estatística F igual a 17,298, significativa a $99 \%$.

31. O capital médio em governos de direita é de $\mathrm{R} \$ 203$ milhões, contra $\mathrm{R} \$ 71$ milhões para a esquerda (significativo em teste de médias a 95\%). 


\section{Eduardo Cesar Marques e Renata Mirandola Bichir}

32. A distância do prefeito, entretanto, não apresenta significância. As correlações são de $-0,278$ (significativo a $99 \%$ ) para secretários e de - 0,114 (significativo a 0,84 ) para prefeitos.

33. As correlações simples entre direita e capital e entre capital e distância do secretário são, respectivamente, 0,17 e -0,28. A correlação parcial de distância e capital, controlada pela direita/esquerda, continua significativa a 95\% e igual a -0,22.

34. A própria variável relativa ao conjunto dos vínculos primários se mostrou inconsistente, já que apresentou significância no geral, mas não voltou a apresentar nos modelos por tipo de governo.

\section{REFERÊNCIAS BIBLIOGRÁFICAS}

AMARAL, A. (1995), Ato Administrativo, Licitações e Contratos Administrativos. São Paulo, Malheiros Ed.

BEZERRA, M. (1995), Corrupção: Um Estudo sobre Poder Político e Relações Pessoais no Brasil. Rio de Janeiro, Relume Dumará/AnPocs.

. (2000), Em Nome das Bases. Rio de Janeiro, Relume Dumará.

BOBBIO, N. (2001), Direita e Esquerda: Razões e Significados de uma Distinção Política. São Paulo, Ed. UNESP.

BRESSER PEREIRA, L. (1998), “A Reforma do Estado dos Anos 1990: Lógica e Mecanismos de Controle". Lua Nova, no 45.

CAMARGOS, R. (1993), Estado e Empreiteiros no Brasil: Uma Análise Setorial. Dissertação de Mestrado, IFCH, Campinas, SP.

CARDOSO, F. H. (1970), "Planejamento e Política: Os Anéis Burocráticos”, in B. Lafer (ed.), Planejamento no Brasil. São Paulo, Ed. Perspectiva.

DAMATTA, R. (1978), “Você Sabe com Quem Está Falando? Um Ensaio sobre a Distinção entre Indivíduo e Pessoa no Brasil", in Carnavais, Malandros e Heróis: Para uma Sociologia do Dilema Brasileiro. Rio de Janeiro, Zahar Ed.

DRAIBE, S. (1989), “As Políticas Sociais Brasileiras: Diagnósticos e Perspectivas”. Políticas Sociais e Organização do Trabalho, n 4 - Para a Década de 90: Prioridades e Perspectivas de Políticas Públicas. Brasília, IPEA/Plan.

FIORI, J. L. (1995), Em Busca do Dissenso Perdido: Ensaios Críticos sobre a Festejada Crise do Estado. Rio de Janeiro, Insight Ed.

FREEMAN, L., WEBSTER, C. e KIRKE, D. (1998), “Exploring Social Structure Using Dynamic Tridimensional Color Images". Social Networks, nำ 20. 
GEDDES, B. e RIBEIRO NETO, A. (2000), “Fontes Institucionais da Corrupção no Brasil”, , in K. Rosenn e R. Downes (orgs.), Corrupção e Reforma Política no Brasil: O Impacto do Impeachment de Collor. São Paulo, Fundação Getulio Vargas Editora.

GRAU, E. e BELLUZZO, L. (1995), “A Corrupção no Brasil”. Revista Brasileira de Estudos Políticos, $\mathrm{n}$ 으. 80 .

LANNA, M. (1997), A Dívida Divina: Troca e Patronagem no Nordeste Brasileiro. Campinas, SP, Ed. UNICAMP.

LESSA, C. e DAIN, S. (1982), “Capitalismo Associado: Algumas Referências para o Tema Estado e Desenvolvimento", in L. Belluzo e R. Coutinho (orgs.), Desenvolvimento Capitalista no Brasil: Ensaios sobre a Crise. São Paulo, Ed. Brasiliense.

MARQUES, E. (1999a), “Estado e Empreiteiras na Comunidade de Políticas Urbanas no Rio de Janeiro". Dados, vol. 42, no 2, pp. 341-385.

. (1999b), Estado e Serviços Urbanos no Final da Década de 1990. Trabalho apresentado no Encontro Internacional Democracia, Igualdade e Qualidade de Vida: Desafios para as Cidades do Século XXI. PMPA/ANPUR, Porto Alegre.

. (2000), Estado e Redes Sociais: Permeabilidade e Coesão nas Políticas Urbanas no Rio de Janeiro. Rio de Janeiro, Revan/FAPESP.

e BICHIR, R. (2001a), “Padrões de Investimento Estatal em Infra-Estrutura Viária em São Paulo 1978-98". Revista São Paulo em Perspectiva, vol. 15, no 1.

. (2001b), "Estado e Espaço Urbano - Revisitando Criticamente as Explicações Correntes sobre as Políticas Estatais Urbanas". Revista de Sociologia e Política, vol. 15.

. (2001c), “Investimentos Públicos, Infra-Estrutura Urbana e Produção da Periferia em São Paulo". Revista Espaço e Debates, no 42.

MEIRELLES, H. (1995), Direito Administrativo Brasileiro (20ª ed.). São Paulo, Malheiros.

NUNES, E. (1997), A Gramática Política do Brasil: Clientelismo e Insulamento Burocrático. Rio de Janeiro, Jorge Zahar/ENAP.

PASQUINO, G. (1993), "Corrupção", in N. Bobbio, N. Matteucci e G. Pasquino (eds.), Dicionário de Política. Brasília, Ed. UnB.

SCOTT, J. (1992), Social Network Analysis. Newbury Park, Ca., Sage Publications.

SKOCPOL, T. (1992), Protecting Soldiers and Mothers: The Political Origins of Social Policy in the United States. Cambridge, Harvard University Press.

STEINMO, S., THELEN, K. e LONGSTRETH, F. (1992), Structuring Politics: Historical Institutionalism in Comparative Analysis. Cambridge, Cambridge University Press.

TILLY, C. (1992), Big Structures, Large Processes and Huge Comparisons. New York, Russel Sage Foundation.

WASSERMAN, S. e FAUST, K. (1994), Social Network Analysis: Methods and Applications. Structural Analysis in the Social Sciences (vol. 8). Cambridge, Cambridge University Press. 


\section{ABSTRACT \\ State and Contractors II: Permeability and Urban Policies in São Paulo (1978-98)}

This article discusses the patterns in relations between the public and private sector in the development of a public policy. We study the relationship between the state and private companies in urban infrastructure policies in São Paulo from 1978 to 1998 . The article conducts an intense dialogue with a previous study on basic sanitation policy in Rio de Janeiro, as presented by Marques (1999a and 2000). As we discuss the conditioning factors for winning bids in public tenders, we highlight the importance of relations among individuals, groups, and organizations in the engineering community by analytically constructing the category "permeability" and utilizing social network analysis as our method.

Key words: public policies; state; social network analysis; interest intermediation; economic sociology

\section{RÉSUMÉ \\ État et Constructeurs II: Perméabilité et Politiques Urbaines à São Paulo (1978-98)}

Dans cet article, on examine les modèles de relations entre secteur public et privé pendant le déroulement d'une politique publique. On a étudié les relations entre l'État et les entreprises privées dans les politiques relatives à l'infrastructure urbaine à São Paulo entre 1978 et 1998. On a établi une comparaison étroite avec une recherche précédente sur la politique d'assainissement de base à Rio de Janeiro, présentée par Marques (1999a et 2000). Au moment d'expliquer les facteurs déterminants de la victoire des constructeurs lors des appels d'offre, on a mis en évidence le système de relations entre individus, groupes et associations dans la communauté des ingénieurs. Dans ce but, on a élaboré la catégorie de perméabilité, utilisant comme méthode l'analyse de réseaux sociaux.

Mots-clé: politiques publiques; État; analyse de réseaux sociaux; médiation d'intérêts; sociologie économique 